\title{
The Question of Capacity: Why Enculturated and Trained Animals have much to Tell Us about the Evolution of Language
}

\author{
Heidi Lyn ${ }^{1}$
}

Published online: 24 January 2017

(C) Psychonomic Society, Inc. 2016

\begin{abstract}
For more than a century researchers have used enculturated animals - those extensively trained or reared by humans - to explore the effects of learning and environment on the capacities for linguistic abilities outside of the human line. Unfortunately, due to many controversies, the findings of these studies frequently have been dismissed or outright ignored. However, experimental exploration of the capacities of nonhumans is the only option to determine which, if any, language-associated capacities are unique to humans. Researchers continue to publish findings from language projects that move our understanding forward, including descriptions of capacities, such as gestural comprehension, declarative communication, and categorization, that are frequently considered to be specific biological adaptations.
\end{abstract}

Keywords Animal and human associative learning ·

Animal cognition · Animal social learning .

Language comprehension

A central question concerning human language evolution is whether other species have biological capabilities to learn and use language. One research method extensively used to approach this question in the past was to raise animals (most often great apes) in language-enriched environments. The primary research question was, and still is, given the correct environment, can humans' closest evolutionary relatives acquire any language-relevant abilities? These studies have typically been most strongly associated with well-known projects

Heidi Lyn

heidi.lyn@usm.edu

1 University of Southern Mississippi, 730 E. Beach Blvd., Long Beach, MS 39560, USA from the 1960s and 1970s in which apes were reared with American Sign Language (Gardner \& Gardner, 1969; Miles, 1994; Patterson, 1978; Terrace, 1979). There were even earlier studies of apes reared in human homes (Furness, 1916; Hayes, 1951; Kellogg \& Kellogg, 1933) looking at the potential for vocal language; however, beginning with the Gardners' rearing of Washoe, later apes were almost all reared in carefully constructed laboratory settings involving nonvocal communication. While these environments are in truth quite different, they are generally discussed under the umbrella term of enculturation.

Enculturation usually refers to the environment of an animal that has had extensive human interaction and in particular has concentrated exposure to human (or a created human-like) language but also can include various amounts of training (in the form of operantly conditioning specific behaviors), testing, and teaching (a catch-all for techniques such as molding, modeling, etc.). However, different researchers use the term enculturation differently and its use can refer to wildly different environmental and social exposure. In the initial sign language studies, the research environments were enriched by home-like furniture, appliances, toys, etc., and many types of training and teaching were employed and detailed in their methods (Gardner \& Gardner, 1969; Gardner, Van Cantfort, \& Gardner, 1992). These techniques were remarkably successful and the subsequent findings were extremely influential and widely reported in the popular media. However, as detailed in Pepperberg (2016, this issue), the field quickly became massively controversial following the publication of several reports from a study by Herb Terrace et al. (1979, 1980) concerning a chimpanzee named Nim Chimpsky, and a subsequent conference that was unprecedented in making systematic attacks on ape "language" researchers and their findings (Sebeok \& Rosenthal, 1981). 
Many issues were discussed in these critiques of the ape language projects, but possibly the most substantial metho dological criticism was the potential interference in meaningful data collection by humans in the environment. Specifically, the critics focused on the possibility that the apes' signing sequences were direct imitations of their caregivers (imitation in this case refers to copying of the specific motor movements, as used by Byrne \& Bates, 2010; Tomasello \& Call, 1997; Whiten, Custance, Gomez, Teixidor, \& Bard, 1996-this kind of imitation is sometimes called mimicry). Because researchers (and Terrace in particular) were specifically interested in examples of syntactical structure in sign sequences, they considered any signs that were directly influenced by human caregivers to invalidate the entire sequence.

While the focus of the criticisms were the ape language projects, particularly those that used sign language, encul turated animal projects included ape studies utilizing alternate methods (Matsuzawa, 1985; Premack, 1971; Rumbaugh, 1978; Savage-Rumbaugh \& Savage-Rumbaugh, 1987please note that in all cases a representative publication is cited, but the contribution to the scientific literature of these projects, those cited below, and others in the field are wide ranging) or other species including dolphins, sea lions, and parrots (Herman, Richards, \& Wolz, 1984; Pepperberg, 1992; Schusterman \& Krieger, 1986) to name the most wellknown. These studies used many mechanisms for communication, including sign language, mechanical and printed symbols, computer-generated sounds, novel gestures, and spoken English. Whereas several of these researchers (Pepperberg, Matsuzawa) did not intend for their projects to be languagespecific, but instead to be explorations into cognitive abilities using language-like communicative tools, they also saw the impact of the critical wave unleashed by the ape study critiques, and adjusted their methodologies to minimize human interaction, particularly during testing.

More than simply spurring scientists into more controlled methods, however, the critiques also inspired a backlash in publication and funding that reverberates to the present day. In general, there is a strong tendency to disregard studies in which animals are trained or enculturated into using humanlike language (see Pepperberg 2016 for more discussion). This concern seems to have expanded beyond scientifically valid skepticism into an unjustified attitude that any animal that has any interaction with people is now somehow "tainted." Indeed, many publications on language abilities in nonhu mans in recent years have utterly failed to reference encul turated animal findings, or only reference them fleetingly, with a dismissal due to the fact that the animals had considerable human contact (e.g. Liszkowski, Schäfer, Carpenter, \& Tomasello, 2009; Scott-Phillips, 2014). The apparent assumption is that due to the human influence, these data cannot inform us about the evolution of language. These attitudes and dismissals also have been part of grant reviews, and as a result, new studies of enculturated animals have effectively ceased. At the moment, there are no scientifically funded enculturation projects with any species in the United States, and I am not aware of any outside of the United States, either.

Notably, while research that specifically references enculturation in animals has been undersupported, in other studies that have gained considerable attention, animals who are clearly benefitting from some level of enculturation are presented as "untrained" and therefore lacking the taint of human influence. This is particularly true of dogs (although see below for some discussion of socialization as a factor in dogs and wolves), but it also applies to dolphins that have been heavily trained, tested, and had regular human interaction throughout their lives (Herman et al., 1999). Crucially, many researchers also underemphasize the potential effects of enculturation on infants. Any number of comparative studies on apes and human infants and even children up to 2.5 years old have concluded with an argument for innate capacities, ignoring entirely the fact that human infants are the most enculturated creatures on the planet (Herrmann, Call, Hernàndez-Lloreda, Hare, \& Tomasello, 2007; Liszkowski, Schäfer, Carpenter, \& Tomasello, 2009).

The key distinction is between typical abilities - those that are shown in natural circumstances - and potential abilities (capacities) - those that may not occur except in extraordinary circumstances or given unusual events or training. Given that humans developed language and that animals do not exhibit human language-like communication in the wild (although complex communication in the wild is well established for many species and is of great interest to the study of language evolution), it often is assumed that animals do not have even the capacity to learn human language (or any more specific language abilities) - and thus that the set of abilities that make up human language evolved at some point in the human lineage after the split between the common ancestors of humans and the great apes. However, this assumption is problematic at each level — not only is it unknown whether lang uage-specific abilities exist at all (or whether language is an exaptation from other capacities) if they do exist, it is still unknown whether those abilities (some or all of them) are, in fact, unique to humans.

Hauser, Chomksy, and Fitch (2002) tried to clarify potential future directions for language evolution researchers. They argued that the abilities that are utilized by language (but not specific to language) could be termed the Faculty for Lang uage Broadly defined (FLB) and the abilities that are specific to human language and therefore necessarily unique to humans could be termed the Faculty for Language Narrow (FLN). Their suggestion was that the abilities in the FLN would be the abilities that humans developed specifically to support language, and the delineation of these abilities would help define the evolutionary pressures that led to the development of language. In this conception, it is assumed that there 
was a biological event that separated nonlanguage-using animals from language using humans. Hauser, Chomsky, and Fitch (2002) did admit the FLN could be empty - that there were no abilities that were specific to human language, but considered that to be a remote possibility at best. They, and most who study language evolution, presuppose at least some abilities that are specific to language AND only found in humans.

However, there is a potential alternative explanation for the absence of human-like language in nonhumans in the wild. Some animals may have the capacity to learn language (or some particular aspects of language) but only exhibit that capacity in specific environments, or with specific teaching. If this were the case, we would no longer be forced to postulate a potential biological event or events that took us from nonlang uage-users to language users. Rather, the environment - social, cultural, or other - would become a key, driving agent of language development. This line of questioning is not new: the Gardners, and most particularly, David Premack (Gardner, Gardner, \& Van Cantfort, 1989; Premack, 1985) described the differences in capabilities of apes that had more versus less enculturation in some detail. However, the usefulness of this perspective seems to be ignored mostly in the current debates.

It is most likely that neither of these explanations is sufficient to explain the anomaly that is human language on their own. Instead, as with almost any evolutionary path, there were likely both biological changes and societal/cultural changes (both nature and nurture) that combined to create the unique form of communication that is language. There are in principle two scientific paths open when attempting to delineate nature/ nurture effects on language. First, what would children do if they grew up without language? Second, what would nonhuman animals do if given access to an environment rich with human language?

We cannot ethically design experimental studies to test the limits of nature and nurture on humans. We cannot raise babies without language, nor can we raise them without social interaction. The closest we can get are observational studies of feral children and deaf children raised without sign language, which are nonexperimental by definition and outside the scope of this paper, but certainly also important additions to the literature on this topic. The ONLY experimental, controlled option for separating biology from environment in language learning is to rear nonhuman animals in enculturated environments and determine what, if any, language abilities they can acquire.

\section{Enculturation studies}

In 2012, I published a review of the ape language studies (there has been no thorough review of the nonprimate literature to date) detailing findings in semantic production and comprehension as well as basic syntactical findings. The earliest animal language work showed many specific lang uage-like abilities were within the semantic capacity of great apes including, but not limited to: associations between noniconic symbols and their referents; the ability to use those symbols semantically; creation of novel signs; functional use of symbols; and communicative innovations, although the evidence for syntactic capacities was more limited (Lyn, 2012). Problematically, many researchers specifically trained word order as a required part of the "language" use - making those data inadequate to detail syntactical knowledge apart from associative conditioning. Some studies that did not train word order did report some syntactical capabilities: comprehension of specific WH-questions and comprehension of English sentences at the level of a 2.5 year old child (SavageRumbaugh et al., 1993). However, this last test did not specifically report on syntactical minimal pairs, making inferences about abilities related to syntax difficult (Lyn, 2012). The Terrace criticisms, on the negative side, suggested that those of Nim's sequences that looked syntactical often were direct imitations of the humans in the environment and therefore argued that all of these early syntactical data (which were collected through data diaries) were equally suspect. In more recent studies, data diaries, when used, included a code for directly imitated utterances, and these are eliminated from consideration (Lyn, Greenfield, \& Savage-Rumbaugh, 2011; Lyn, Greenfield, Savage-Rumbaugh, Gillespie-Lynch, \& Hopkins, 2011).

As an answer to some of the questions regarding syntax, my colleague Patricia Greenfield began a series of studies that we have continued - exploring symbol combinations in both primates and children, focusing on sequencing rules found in very early language users - semiotic ordering (Greenfield \& Savage-Rumbaugh, 1990; Lyn, Greenfield, \& Savage-Rum baugh, 2011). One clear finding is that both children and great apes can and do have preferential word ordering patterns based on the meaning of symbols rather than simply their syntactic category. In addition, the ordering preferences in apes are similar in type and style to the earliest stages of syntactic development in children. By focusing on fully developed syntax in adult humans, the early researchers missed an important similarity between apes and humans and frequently (and I think incorrectly) argued that syntax was the proverbial linguistic Rubicon that humans had to cross.

The other main argument made by Terrace hinged upon the imitative capabilities of apes. According to his argument, the conversational data of the apes in the animal language studies was tainted, because the apes imitated many of their constructions. This argument does not hold up well for many reasons. First, in a recent study that used diary data collected with the same methodologies in apes and children, we showed that children actually imitated their caregivers in conversation 
more often than apes did (Lyn, Greenfield, Savage-Rum baugh, et al., 2011). If imitations are accepted as a sure-fire indication of nonlanguage use, we would have to conclude that the apes were better at using language than children were.

Second, later researchers directly contradicted the imitation argument with a series of studies suggesting that apes do not directly imitate humans well at all (Whiten et al., 1996). In these studies, chimpanzees and human children were given puzzle box (artificial fruit) and watched a model open the box. The children imitated all of the model's movements, including some that were clearly ineffective or irrelevant, whereas the chimpanzees emulated the types of movements but did not copy all motions exactly and skipped some movements completely. These researchers interpreted these findings to suggest that humans had developed the capacity for direct imitation after the split with our common ancestor with apes.

The contradiction between Terrace's findings of copious "imitation" and later researchers' findings of minimal imitation may be due to the enculturation (level of human interaction in the environment) of the apes in question. Considerable data suggest well-developed general social learning abilities in apes (including goal emulation, social facilitation, etc.), but the specificity of imitation per se seems to be limited to apes who were reared with large amounts of human interaction (Tomasello \& Call, 2004), suggesting that the differences in imitation capacity between great apes and humans may be influenced strongly by rearing environment.

Imitation also may be a developmental stage (for both apes and humans). Horowitz (2003) replicated the puzzle box study (above) with adult humans. Adults performed more similarly to the adult chimpanzees than had the children, emulating the movements of the researchers rather than directly imitating them. Additionally, Gillespie-Lyn ch, Greenfield, Lyn, \& Savage-Rumbaugh (2011) showed that children as well as a chimpanzee and bonobo (encul turated and in an animal language project) initially imitated novel communicative constructions made by their caretakers (although sometimes that imitation was delayed by hours or even days) but that direct imitation became less frequent as the participants matured. These findings, and others, may indicate that imitation is utilized extensively by the young in great apes and humans, but that these species switch to a more mature emulation strategy for learning once they have sufficient experience and knowledge. Interestingly, the one species that regularly (and spectacularly) engages in imitation is the bottlenose dolphin (Herman, 2002; Jaakkola, Guarino, \& Rodriguez, 2010). It is unfortunate that dolphin research on cognition, particularly research in which dolphins interact with hu mans, has almost completely halted due to lack of support, funding, and the closure of research labs.
Enculturation also has been shown to have effects on abilities that are not specifically linguistic in nature, although they are likely part of the suite of abilities that support language. A popular topic in comparative communication has been the supposed failure of nonhuman primates to pass the object choice task (Lyn, 2010 for review). This task is a seemingly simple communicative task in which a researcher hides food and then points out the location to a participant. In test after test, nonhuman primates have failed to pass this test (although see meta-analyses that show that even those apes were performing better than the statistical power could measureLyn, 2010; Mulcahy \& Hedge, 2012). However, studies in several labs have suggested that apes' failure on this test is entirely due to learned interaction with humans as opposed to any biological capacity that is lacking in nonhuman primates. When comparing enculturated and nonenculturated apes, those with enculturation not only pass object choice tests, but do so with almost perfect scores (Lyn, Russell, \& Hopkins, 2010; Lyn, 2010).

Dogs generally do better on the object choice task (as do dolphins and several other domesticated species, see Miklósi \& Soproni, 2006 for a somewhat dated review). It has been suggested that dogs could pass the object choice task, because they had been bred to have a cooperative capacity that wolves or great apes did not (the domestication hypothesis; Hare et al., 2010). However, other laboratories have shown that dogs' superior performance on the object choice task only applied to dogs with appropriate enculturation and interaction with humans (Udell, Dorey, \& Wynne, 2010; Udell, Spencer, Dorey, \& Wynne, 2012). Other studies have compared dogs and wolf puppies with similar levels of socialization and concluded that there is a species difference (Gácsi et al., 2009). However, that species disappeared when adults were tested, suggesting that there are alternative explanations to the domestication hypothesis - for example, differing maturation rates. Additionally, it is still possible, even likely, that the type of socialization/enculturation is a major factor in these different results. While the wolves were hand-reared in a human home, they were not likely treated as future pets, because they would soon be released to a wolf sanctuary.

These findings and others highlight the many questions that remain unanswered. In particular, while we have ample evidence of environmental support of communicative/cognitive abilities, we do not know what, in particular, about enculturation environments is supportive of what forms of cognitive abilities. Enculturated animals have environments that differ from conspecific-raised apes in many details. Call and Tomasello (2004) listed differences that included: simple exposure to human life, emulation learning of human actions, explicit training by humans, and being treated by humans as intentional beings. I suggest another factor that has been discussed by others and may prove to be equally important: exposure to extensive cognitive testing. The comparison of 
environment, training techniques, etc., will be an important component of future analyses. In addition to researchers exploring how varied rearing environments affect animals (van Ijzendoorn, Bard, Bakermans-Kranenburg, \& Ivan, 2009), several studies have already shown significantly different findings when their training models are altered (Pepperberg \& Url, 2011; Savage-Rumbaugh \& Savage-Rumbaugh, 1987).

Unfortunately, due to the current unpopularity of encul turated animal projects, combined with the difficulty of rearing apes or other long-lived, cognitively complex species, not to mention mounting pressures from animal rights organizations (note the recent announcements at least partially in response to animal rights groups by: Sea World to cease breeding killer whales (Sea World, 2016), the National Aquarium in Baltimore to move their dolphin colony to a sanctuary ( $\mathrm{Na}$ tional Aquarium of Baltimore, 2016), and the National Insti tutes of Health to cease research funding on chimpanzees (NIH, 2015)), it is unlikely that these questions will be pursued. This is particularly unfortunate given that there may be applications yet to be determined should specific aspects of the cognition- and language-boosting environment be uncovered. In particular, defining environmental features that can support language learning in nonhuman primates would likely be of use to those working with language-delayed children (as argued previously: e.g. Pepperberg \& Sherman, 2000; Sevcik \& Romski, 1995). In summary, enculturation projects may still hold many answers regarding the evolution of language. Sadly, unless researchers in other fields (and granting agencies) begin to appreciate this potential, we might never find those answers.

\section{References}

Byrne, R. W., \& Bates, L. A. (2010). Primate Social Cognition: Uniquely Primate, Uniquely Social, or Just Unique? Neuron, 65(6), 815-830. doi:10.1016/j.neuron.2010.03.010

Furness, W. (1916). Observations on the Mentality of Chimpanzees and Orang-Utans. Proceedings of the American Philosophical Society, 55(3), 281-290.

Gácsi, M., Gyori, B., Virányi, Z., Kubinyi, E., Range, F., Belenyi, B., \& Miklósi, Á. (2009). Explaining dog wolf differences in utilizing human pointing gestures: Selection for synergistic shifts in the development of some social skills. PLoS ONE, 4(8), 4-10. doi:10.1371/journal. pone. 0006584

Gardner, R. A., \& Gardner, B. T. (1969). Teaching sign language to a chimpanzee. Science (New York, N.Y.), 165(894), 664-672. doi:10.1126/science.165.3894.664

Gardner, R. A., Gardner, B. T., \& Van Cantfort, T. E. (1989). Teaching Sign Language to Chimpanzees. SUNY Press.

Gardner, R. A., Van Cantfort, T. E., \& Gardner, B. T. (1992). Categorical replies to categorical questions by cross-fostered chimpanzees. The American Journal of Psychology, 105(1), 27-57. doi:10.2307 $/ 1422980$
Gillespie-Lynch, K., Greenfield, P. M., Lyn, H., \& Savage-Rumbaugh, S. (2011). The role of dialogue in the ontogeny and phylogeny of early symbol combinations: A cross-species comparison of bonobo, chimpanzee, and human learners. First Language, 31(4), 442-460. doi:10.1177/0142723711406882

Greenfield, P. M., \& Savage-Rumbaugh, E. S. (1990). Grammatical Combination in Pan paniscus: Process of Learning and Invention in the Evolution and Development of Language. In S. T. Parker \& K. R. Gibson (Eds.), "Language" and Intelligence in Monkeys and Apes: Comparative Developmental Perspetives (pp. 540-578). New York, NY, US: Cambridge University Press.

Hare, B., Rosati, A., Kaminski, J., Bräuer, J., Call, J., \& Tomasello, M. (2010), The domestication hypothesis for dogs' skills with human communication: a response to Udell et al. (2008) and Wynne et al. (2008). Animal Behaviour, 79(2), e1-e6. doi:10.1016/j.anbehav.2009.06.031

Hauser, M. D., Chomsky, N., \& Fitch, W. T. (2002). The faculty of language: what is it, who has it, and how did it evolve? Science (New York, N.Y.), 298(5598), 1569-1579. doi:10.1126/science.298.5598.1569

Hayes, C. (1951). The Ape in Our House (1st ed.). London: Gollancz.

Herman, L. M. (2002). Vocal, Social, and Self-Imitation by Bottlenosed Dolphins. In K. Dautenhahn \& C. Nehaniv (Eds.), Imitation in Animals and Artifacts (pp. 63-108). Cambridge, MA: MIT Press.

Herman, L. M., Abichandani, S. L., Elhajj, A. N., Herman, E. Y., Sanchez, J. L., \& Pack, A. A. (1999). Dolphins (Tursiops truncatus) comprehend the referential character of the human pointing gesture. Journal of Comparative Psychology, 113(4), 347-364. doi:10.1037 /0735-7036.113.4.347

Herman, L. M., Richards, D. G., \& Wolz, J. P. (1984). Comprehension of sentences by bottlenosed dolphins. Cognition, 16(2), 129-219. doi:10.1016/0010-0277(84)90003-9

Herrmann, E., Call, J., Hernàndez-Lloreda, M. V., Hare, B., \& Tomasello, M. (2007). Humans have evolved specialized skills of social cognition: the cultural intelligence hypothesis. Science (New York, N.Y.), 317(5843), 1360-1366. doi:10.1126/science.1146282

Horowitz, A. C. (2003). Do humans ape? Or do apes human? Imitation and intention in humans (Homo sapiens) and other animals. Journal of Comparative Psychology, 117(3), 325-336. doi:10.1037/07357036.117.3.325

Jaakkola, K., Guarino, E., \& Rodriguez, M. (2010). Blindfolded imitation in a bottlenose dolphin (Tursiops truncatus). International Journal of Comparative Psychology, 23, 671-688. doi:10.1016/j.jebdp.20 05.01.003

Kellogg, W. N., \& Kellogg, L. A. (1933). the Ape and the Child. Optometry and Vision Science (Vol. 10). NY: McGraw-Hill. doi:10.1097/00006324193311000-00009

Liszkowski, U., Schäfer, M., Carpenter, M., \& Tomasello, M. (2009). Prelinguistic infants, but not chimpanzees, communicate about absent entities: Research article. Psychological Science, 20(5), 654 660. doi:10.1111/j.1467-9280.2009.02346.x

Lyn, H. (2010). Environment, methodology, and the object choice task in apes: Evidence for declarative comprehension and implications for the evolution of language. Journal of Evolutionary Psychology, 8(4), 333-349. doi:10.1556/JEP.8.2010.4.3

Lyn, H., Greenfield, P. M., \& Savage-Rumbaugh, E. S. (2011). Semiotic combinations in Pan: A comparison of communication in a chimpanzee and two bonobos. First Language, 31(3), 300-325. doi: $10.1177 / 0142723710391872$

Lyn, H., Greenfield, P. M., Savage-Rumbaugh, S., Gillespie-Lynch, K., \& Hopkins, W. D. (2011). Nonhuman primates do declare! A comparison of declarative symbol and gesture use in two children, two bonobos, and a chimpanzee. Language and Communication, 31(1), 63-74. doi:10.1016/j.langcom.2010.11.001

Lyn, H., Russell, J. L., \& Hopkins, W. D. (2010). The impact of environment on the comprehension of declarative communication in apes. Psychological Science : A Journal of the American Psychological Society / APS, 21(3), 360-365. doi:10.1177/0956797610362218 
Matsuzawa, T. (1985). Colour naming and classification in a chimpanzee (Pan troglodytes). Journal of Human Evolution, 14(3), 283-291. doi:10.1016/S0047-2484(85)80069-5

Miklósi, Á., \& Soproni, K. (2006). A comparative analysis of animals' understanding of the human pointing gesture. Animal Cognition, 9(2), 81-93. doi:10.1007/s10071-005-0008-1

Miles, H. L. W. (1994). ME CHANTEK: The Development of SelfAwareness in a Signing Orangutan. In S. T. Parker, R. W. Mitchell, \& M. L. Boccia (Eds.), Self-Awareness in Animals and Humans: Developmental Perspectives (pp. 254-272). Cambridge, UK: Cambridge University Press.

Mulcahy, N. J., \& Hedge, V. (2012). Are great apes tested with an abject object-choice task? Animal Behaviour, 83(2), 313-321. doi:10.1016 /j.anbehav.2011.11.019

National Aquarium of Baltimore. (2016). The future of dolphin care. Retrieved from http://www.aqua.org/blog/2016/june/future-ofdolphin-care

National Institutes of Health. (2015). NIH will no longer support biomedical research on chimpanzees. Retrieved from https://www.nih. gov/about-nih/who-we-are/nih-director/statements/nih-will-nolonger-support-biomedical-research-chimpanzees

Patterson, F. (1978). Conversations with a gorilla. National Geographic, 134(4), 438-465.

Pepperberg, I. M. (1992). Proficient performance of a conjunctive, recursive task by an African gray parrot (Psittacus erithacus). Journal of Comparative Psychology, 106(3), 295-305. doi:10.1037/07357036.106.3.295

Pepperberg, I. M., \& Sherman, D. (2000). Proposed use of two-part interactive modeling as a means to increase functional skills in children with a variety of disabilities. Teaching and Learning in Medicine, 12(4), 213-220. doi:10.1207/S15328015TLM1204 10

Pepperberg, I. M., \& Url, S. (2011). Social Modeling Theory : A Possible Framework for Understanding Avian Vocal Learning SOCIAL MODELING THEORY : A POSSIBLE FRAMEWORK FOR UNDERSTANDING AVIAN VOCAL LEARNING. Auk, 102(4), 854-864.

Pepperberg, I.M. (2016). Animal language studies: What happened? Psychonomic Bulletin and Review. doi:10.3758/s13423-016-1101-y

Premack, D. (1971). Language in chimpanzee? Science (New York, N.Y.), 172(985), 808-822. doi:10.1126/science.172.3985.808

Premack, D. (1985). "Gavagai!" or the future history of the animal language controversy. Cognition, 19(3), 207-296. doi:10.1016/00100277(85)90036-8

Rumbaugh, D. M. (1978). Language Learning by a chimpanzee. The Lana Project. Journal of Human Evolution (Vol. 7). New York: Academic Press. doi:10.1016/S0047-2484(78)80049-9

Savage-Rumbaugh, E. S., Murphy, J., Sevcik, R. A., Brakke, K. E., Williams, S. L., \& Rumbaugh, D. M. (1993). Language comprehension in ape and child. Monographs of the Society for Research in Child Development, 58(3-4), 1-222. doi:10.2307/1166068

Savage-Rumbaugh, S. E., \& Savage-Rumbaugh, E. S. (1987). Ape language: From conditioned response to symbol. By E. Sue Savage-
Rumbaugh. International Journal of Primatology, 8(3), 293-294. doi:10.1007/BF02735178

Schusterman, R. J., \& Krieger, K. (1986). Artificial language comprehension and size transposition by a California sea lion (Zalophus californianus). Journal of Comparative Psychology, 100(4), 348355.

Scott-Phillips, T. (2014). Speaking Our Minds: Why human communication is different, and how language evolved to make it special. Palgrave MacMillan.

Sea World. (2016). Last Generation. Retrieved from https://seaworldcares. com/en/Future/Last-Generation/

Sebeok, T. A., \& Rosenthal, R. (1981). The Clever Hans phenomenon: communication with horses, whales, apes, and people. Annals of the New York Academy of Sciences (Vol. 364). Annals of the New York Academy of Sciences. doi:10.1016/0277-9536(82)90101-0

Sevcik, R. A., \& Romski, M. A. (1995). Additional support for the role of animal research in the study of human mental retardation. American Journal on Mental Retardation, 100(1), 95-97. Retrieved from http://lynx.lib.usm.edu/login?url=http://search.ebscohost. com/login. aspx ?direct=true $\& d b=b x h \& A N=B A C D 199598474517$ \&site $=$ ehost-live

Terrace, H. S. (1979). Nim (1st ed.). New York: Knopf: Random House.

Terrace, H. S., Petitto, L. A., Sanders, R. J., \& Bever, T. G. (1979). Can an ape create a sentence? Science (New York, N.Y.), 206(4421), 891902. doi:10.1126/science.504995

Terrace, H. S., Petitto, L. A., Sanders, R. J., \& Bever, T. G. (1980). On the grammatical capacity of apes. In K. Nelson (Ed.), Children's language: vol. 2 (Vol. 2, pp. 371-496). New York: Gardner Press.

Tomasello, M., \& Call, J. (1997). Primate cognition. Oxford psychology series, No. 30. New York: Oxford University Press.

Tomasello, M., \& Call, J. (2004). The role of humans in the cognitive development of apes revisited. Animal Cognition, 7(4), 213-215. doi:10.1007/s10071-004-0227-x

Udell, M. A. R., Dorey, N. R., \& Wynne, C. D. L. (2010). What did domestication do to dogs? A new account of dogs' sensitivity to human actions. Biological Reviews, 85(2), 327-345. doi:10.1111 /j.1469-185X.2009.00104.x

Udell, M. A. R., Spencer, J. M., Dorey, N. R., \& Wynne, C. D. L. (2012). Human-Socialized Wolves Follow Diverse Human Gestures ... And They May Not Be Alone. International Journal of Comparative Psychology, 25(2), 97-117.

van Ijzendoorn, M. H., Bard, K. A., Bakermans-Kranenburg, M. J., \& Ivan, K. (2009). Enhancement of attachment and cognitive development of young nursery-reared chimpanzees in responsive versus standard care. Developmental Psychobiology, 51(2), 173-185. doi:10.1002/dev.20356

Whiten, A., Custance, D. M., Gomez, J. C., Teixidor, P., \& Bard, K. A. (1996). Imitative learning of artificial fruit processing in children (Homo sapiens) and chimpanzees (Pan troglodytes). Journal of Comparative Psychology, 110(1), 3-14. doi:10.1037/07357036.110.1.3 